\title{
Religion, religiosity and adolescent risky sexual health behaviour in Lagos Metropolis, Nigeria
}

\author{
Onipede Wusu' \\ Demography and Social Statistics, Covenant University, Ota., Ogun State, Nigeria \\ wusu.onipede@covenantuniversity.edu.ng
}

\begin{abstract}
The rate of premarital sexual intercourse among adolescents in Nigeria is alarming, despite its prohibition by several religious groups. This contradiction prompted the question: what is the prevailing relationship between religion, religiosity, and adolescents' sexual behaviour in the country? This relationship was examined through survey data collected between December 2009 and February 2010 in the Lagos metropolis. A multistage sampling procedure was adopted in selecting 1026 adolescents between 12 and 19 years of age in the metropolis ${ }^{2}$ and Logistic regressions techniques were employed in data analysis. Results reveal that religious affiliation is significantly related to only casual sexual relationships among boys at the level of ${ }^{2}$ analysis $(p<0.05)$ but it is not significantly related to any of the indicators of risky sexual behaviour at multivariate level of analysis. Also, religiosity is significantly related $(p<0.05)$ to multiple sexual partnerships at both levels of analysis among females. The study concludes that religious affiliation is not likely to play any significant role in combating adolescents' risky sexual behaviour but religiosity could be fairly effective in this battle among females in the study setting.
\end{abstract}

Keywords: religion, religiosity, adolescents, sexual health behaviour, Lagos, Nigeria

\section{Introduction}

Over $22 \%$ of the population of Nigeria are adolescents. Adolescence is described as "a time of transition, change and heightened vulnerability during which adolescents feel pressured by and caught up between internal needs and societal demands" (Doswell, Kouyate, \& Taylor, 2003: 195). Young people undergoing this period are characterised by risky sexual behaviour such as early sexual initiation, multiple sexual partnership and casual unprotected sex, in sub-Saharan Africa (Bankole \& Malarcher, 2010). Consequences of these risky sexual practices include sexually transmitted infections, HIV/ AIDs, unwanted pregnancies, abortions and adolescent parenting (Morhason-Bello et al., 2008). Such consequences undermine their sexual health. Behavioural change is therefore imperative to curb these health consequences. This paper examines the role religion and religiosity can play in this regard.

In the last three decades, there has been an unprecedented proliferation of religious outfits and a new wave of religiosity observable in all nooks and crannies of the country. Many denominations or sects have sprung up among the two popular religious groups - Christianity and Islam - in the country. The 2008 Demographic and Health Survey (DHS) indicates that most Nigerians are involved in the two popular religious groups (Christianity $=54 \%$ and Islam $=44 \%$ ) while only $2 \%$ fall into no religious or traditional category (National Population Commission \& ICF Macro, 2009).

In spite of the apparent pervasive religiosity in the country, pre-marital sexual practices that are prohibited by these religions are not abating among adolescents (Dorojaiye, 2009; Morhason-Bello et al., 2008; Okonofua, 2007). The National Population Commission (NPC) notes that by 18 years of age, $49 \%$ of females and $36 \%$ of their male counterparts have had sex mainly outside marriage ( $h t t p: / / w w w . p o p u l a t i o n . g o v . n g / i n d e x . p h p)$. Given this scenario, the question of interest in this study is: what role are religious affiliation and religiosity playing in the sexual behaviour of adolescents in the country? Can religious affiliation and religiosity be utilised as a channel through which risky sexual behaviour can be managed? These questions are critical in view of the growing evidence that behavioural change is essential to curbing the fast spreading HIV pandemic in sub-Saharan Africa (Genuis, 2009; Santow, 2009).

As pointed out by Fehring, German, Cheever \& Philpot (1998), from a public-health angle, it is an important goal to devise ways of assisting young people to prevent unprotected sex. According to them, a way of driving this is to encourage their involvement in religious activities. The findings of that study re-echoed the proposition that religion is a key factor in shaping [sexual] behaviour in society (Olurode, 2000). Other studies testing this hypothesis have examined different aspects. Some studies examined the effect of religious affiliation on pre-marital sexual behaviour among adolescents and reported existence of causal relationship. Thus adolescents who identify with religious groups tend to refrain from premarital sexual permissiveness. This constraining effect of religious affiliation is reportedly very high among adolescents who attend Church or religious meetings (Morhason-Bello et al., 2008; Nishimura et al., 2007; Price \& Granger, 2005; Thornton \& Camburn, 1989).

I. Wusu Onipede, PhD, is a Senior Lecturer in Demography and Social Statistics, School of Social Sciences, College of Development Studies, Covenant University, Nigeria 
Religiosity is a crucial variable in studies that have considered the relationship between religion and adolescent sexual behaviour. It has been measured in various studies in terms of the frequency of religious attendance, level of involvement in religious activities and the level of spirituality. Available literature indicates that religiosity tends to exert a constraining effect on the attitude of adolescents towards involvement in sexual activity (Fehring et al., 1998; Thornton \& Camburn, 1989). Previous studies reported that higher level of religiosity is very likely to delay sexual initiation among young people (Barnett et al., 20 10; Etzkin, 2004; Hardy \& Raffaelli, 2003; Rostoky, Regrerus, \& Wright, 2002; Steinman \& Zimmerman 2004).

However, the findings of these studies reveal three unresolved differences. First, that religiosity is only significantly related to adolescent sexual behaviour at the point of sexual initiation. In this light, once sexual initiation occurs, religiosity ceases to be a significant predictor of adolescent sexual behaviour (e.g. Hardy \& Raffaeli, 2003; Rostoky, Regrerus, \& Wright, 2002). Contrariwise, other studies have shown that a high level of religiosity still exerts constraining effect on adolescent sexual behaviour after sexual initiation (e.g. Fehring et al., 1998; Odimegwu, 2005; Thornton \& Camburn, 1989). The second unresolved difference is the gender dimension. Some studies report that religiosity is a significant constraining factor among males and females (e.g. Rostoky, Regrerus, \& Wright, 2002). Conversely, others indicate that the suppressive effect of religiosity on sexual behaviour is significant among females and not among males (e.g. Meier, 200I; Rostosky, Wilcox, Wright, \& Randall, 2004). Thirdly, some studies report that a significant relationship between religiosity and adolescent sexual behaviour is observed only when basic demographic characteristics are not controlled (e.g. Jones, Darroch \& Singh, 2005) while some others indicate that the relationship is significant even when such characteristics are controlled (e.g. Steinman \& Zimmerman, 2004).

The above unresolved differences point to the necessity of further studies. Hence the present study, which seeks to contribute directly to the second unresolved difference. Within this context, two hypotheses are tested. First, religious affiliation is likely to significantly influence risky sexual behaviour differently among male and female adolescents in the study population. Second, religiosity is likely to significantly affect risky sexual behaviour differently among male and female adolescents. Through these hypotheses, the study seeks to explain the likelihood that religious affiliation and religiosity would influence risky sexual behaviour among boys and girls in the study population.

\section{Methods}

\section{Settings and sampling}

This study was carried out in Lagos State, the commercial capital of Nigeria. Its natural harbour and the population have positioned the state since independence as the most industrial city in the country. The state has an estimated population of over 18.8 million (projecting with $2.6 \%$ growth rate). This projection was based on the estimate by Lagos State Ministry of Science and Technology in 2006. This baseline database has been used because of the availability of data for the 20 Local Government Areas (LGAs). The state is considered appropriate for this study on two grounds: it is the melting point for religious activities and it is typical of the religious diversity in the country. In addition, the population of the metropolitan part of the state reflects virtually every ethnic group in the country.

A multistage sampling procedure was adopted owing to the unavailability of a useful sampling frame in the city. In the metropolis, within the limits of available resources, two of the LGAs were purposely selected to represent high income, sparsely populated residential area (Ikeja LGA) and low income, densely populated residential area (Ajeromi-Ifelodun LGA). The two LGAs have a population size of 2.3 million representing 12.3 percent of the estimated population for the state. Permission to undertake the study in the two LGAs was sought and was granted by the management of respective LGAs.

In each LGA, the number of wards was identified and a list of all wards prepared. The wards are the political demarcations in the country for electoral purposes. Considering the resources available for this study, in Ajeromi-Ifelodun LGA, one ward was randomly selected out of 10 and one was also selected out of six in lkeja LGA. There were 82 streets in the ward selected in Ajeromi-Ifelodun LGA and 32 in the one selected in Ikeja LGA. Five percent of the streets in Ajeromi-Ifelodun LGA were randomly selected leading to four streets that were used for the survey in the LGA. On the other hand, because the number of streets in Ikeja is limited $20 \%$ of the 32 streets in lkeja were randomly selected owing to the fact that the population is sparsely distributed. Buildings on the selected streets were counted and thereafter selected through a random process. In each selected building, one household was chosen randomly and one eligible adolescent interviewed after obtaining their consent (parents of those in junior secondary school did on behalf of their children) after the purpose of the study had been explained to them. A face- to-face interview was employed by four field assistants in the administration of the questionnaires. In all, 1026 adolescents within the age bracket of $12-19$ years were interviewed (see Table I for respondents' socio-demographic characteristics). The study population is situated in the

Inkanyiso, Jnl Hum \& Soc Sci 20I I, 3(I) 
context of the generally agreed definition of adolescents as young people between ages 10 to 19 years, experiencing the period of transition from childhood to adulthood (Bankole \& Malarcher, 2010).

\section{Measurement}

Data analysed in this paper were generated from structured questionnaire designed for a larger study. This questionnaire was pretested by administering 20 copies among young people. The analysis of the data elicited at this level assisted in ensuring the face validity of the instrument. Among other variables, questions were asked to measure religious affiliation, religiosity and indicators of risky sexual behaviour in the instrument. Religion/religiosity was measured through two questions: what is your religious affiliation and how regular do you attend to religious activities (options provided include once a year, once a month, once a week, twice a week and more than twice a week)? Risky sexual behaviour was measured through the following questions; have you experienced sexual intercourse before (yes or no)? How old were you when you experienced the first had sexual intercourse? Did you have a regular sex partner(s) in the last six months (yes or no)? Or did you have sex with just anyone who came your way (yes or no)? How many sexual partners did you have in the last six months (one or more than one)? Did you use a male or female condom during intercourse in the last six months (yes or no)?

From the last set of questions, the indicators of risky sexual behaviours were generated. These indicators include multiple sexual partnerships (how many sexual partner(s) did you have in the last six months)?; in this case more than "one" response was classified as 'yes' and one as 'no'), age at first sexual intercourse (how old were you when you experienced the first sexual intercourse?), casual sexual encounters (or did you have sex with just anyone who came your way in the last six months?) and unprotected sex (did you use the male or female condom last six months?).

\section{Ethical consideration}

Although an ethics committee does not exist in the University, ethical issues were adequately taken care of. The anonymity of the respondents was paramount in the design of the questionnaire. The face-to-face procedure adopted in the interview ensured that respondents' privacy, to a very large extent, was guaranteed. The respondents were free to decide to participate or not in the study.

Analysis

Data were entered into the SPSS 16.0 data editor directly, cleaned and necessary recoding was carried out. Bivariate analysis was conducted on the association between religion, religiosity and the indicators of risky sexual behaviour. The chi-square technique was used in testing associations between two variables. Religiosity was computed from the question on 'how regular do you attend to religious activities'? The five possible responses were collapsed into three on an ordinal scale: religious (once a year plus once a month), more religious (once a week) and most religious (twice a week or more).

Three logistic regression models were constructed at the multivariate level of analysis. Dependent variables for the logistic regression models were having more than one sexual partner within the six months preceding the survey, engaging in casual sex six months preceding the survey and did not use condom during sexual intercourse six months preceding the survey. All these variables were re-coded to read "0" or "I". At all levels of analysis, boys and girls were analysed separately in order to highlight gender differential.

\section{Results}

Table I shows percentage distribution of respondents by religion, religiosity and gender. Most of the respondents were Protestants (Male $=37 \%$ and Female $=41 \%$ ) and Catholic Christians (Male $=29 \%$ and Female $=27 \%$ ). Islam has the third largest membership among the sampled adolescents. The level of religiosity among the respondents was moderately high but female respondents appeared most religious. Over $90 \%$ of both male and female respondents were never married. A large proportion of the respondents had completed secondary education - male (76\%) and females (7I\%). As shown in the table, the majority of the respondents were living with their parents and were not consumers of alcohol, cigarettes and hard drugs. And a higher proportion of male respondents (35\%) than their female counterparts (24\%) were sexually active.

Table 2 presents the bivariate analysis (using the chi-square $\left(X^{2}\right)$ technique) of the association between religious affiliation, religiosity and the indicators of risky sexual behaviour (casual sex, having more than one sexual partners, unprotected sexual intercourse and age at first sexual intercourse) among the respondents. In the table, religious affiliation and casual sex were significantly associated among males $(P<0.05)$. The incidence of casual sex is highest among males who were Traditionalist or of no religious affiliation (67\%) and lowest among the Protestants (17\%). Having more than one sexual partner was only significantly associated with religiosity among female respondents. Those who were most religious reported the lowest cases of multiple sexual partnerships (24\%) compared to $73 \%$ among those who were just religious. Unprotected sex was only significantly associated with religiosity among males $(P<0.05)$. Surprisingly, 
the data indicate that a positive relationship exist between religiosity and unprotected sex among the male respondents. More religious males engaged in unprotected sex than their counterparts who were less religious.

Table I Percentage distribution of survey respondents by socio-demographic characteristics and sex

\begin{tabular}{|c|c|c|}
\hline Characteristics & Male & Female \\
\hline & $n=498$ & $n=528$ \\
\hline \multicolumn{3}{|l|}{ Local Government Area } \\
\hline Ajeromi-Ifelodun & 48.8 & 57.6 \\
\hline Ikeja & 51.2 & 42.4 \\
\hline Average age & 16 & 16 \\
\hline \multicolumn{3}{|l|}{ Religious Affiliation } \\
\hline None/Traditional & 4.0 & 2.1 \\
\hline Islam & 30.1 & 30.5 \\
\hline Catholic & 28.5 & 26.9 \\
\hline Protestants & 37.4 & 40.5 \\
\hline \multicolumn{3}{|l|}{ Religiosity } \\
\hline Religious & 12.8 & 10.9 \\
\hline More religious & 50.0 & 45.6 \\
\hline Most religious & 37.2 & 43.5 \\
\hline \multicolumn{3}{|l|}{ Marital Status } \\
\hline Never married & 93.8 & 92.7 \\
\hline Cohabiting & 3.3 & 2.1 \\
\hline Married & 0.6 & 3.9 \\
\hline Separated/divorce & 0.6 & 0.4 \\
\hline Average age at first marriage & 17 & 16 \\
\hline \multicolumn{3}{|l|}{ Education } \\
\hline None & 0.6 & 1.1 \\
\hline Primary school & 3.1 & 4.6 \\
\hline Junior secondary school & 18.4 & 22.8 \\
\hline Senior secondary school & 75.7 & 70.7 \\
\hline Tertiary & 2.2 & 0.8 \\
\hline \multicolumn{3}{|l|}{ Living with Parents } \\
\hline Yes & 80.7 & 80.4 \\
\hline No & 19.3 & 19.6 \\
\hline \multicolumn{3}{|l|}{ Drink/Smoke } \\
\hline None & 71.1 & 81.6 \\
\hline Alcohol & 17.5 & 8.3 \\
\hline Cigarette & 6.0 & 3.2 \\
\hline Hard drugs & 5.4 & 6.8 \\
\hline \multicolumn{3}{|c|}{ Experienced sexual intercourse before } \\
\hline No & 64.6 & 76.3 \\
\hline Yes & 35.4 & 23.7 \\
\hline
\end{tabular}


Table 2 Bivariate analysis of survey respondents on the association between religion, religiosity and indicators of sexual health behaviour

\begin{tabular}{|c|c|c|c|c|c|c|}
\hline \multirow[t]{3}{*}{ Characteristics } & \multicolumn{2}{|c|}{ Casual Sex } & \multicolumn{2}{|c|}{ More than one sex partner } & \multicolumn{2}{|c|}{ Did not use condom } \\
\hline & $\mathbf{M}$ & $\mathbf{F}$ & $\mathbf{M}$ & $\mathbf{F}$ & $\mathbf{M}$ & $\mathbf{F}$ \\
\hline & \multicolumn{6}{|c|}{ Percent } \\
\hline \multicolumn{7}{|l|}{ Religious Affiliation } \\
\hline None/traditionalist & $66.7 *(6)$ & na & $80.0(10)$ & na & $50.0(14)$ & na \\
\hline Islam & $27.7 *(22)$ & na & $44.4(45)$ & $4 I .9(3 I)$ & $49.0(51)$ & $65.5(4 I)$ \\
\hline Catholic & $18.4 *(38)$ & na & $56.6(25)$ & $50.0(26)$ & $45.5(44)$ & $54.3(35)$ \\
\hline Protestants & $17.2 *(29)$ & na & $41.9(31)$ & $31.0(29)$ & $53.1(49)$ & $59.5(42)$ \\
\hline \multicolumn{7}{|l|}{ Religiosity } \\
\hline Religious & na & na & $60.0(10)$ & $72.7 *(I I)$ & $33.3 *(15)$ & $42.9(14)$ \\
\hline More religious & $21.6(37)$ & na & $41.7(48)$ & $50.0 *(36)$ & $40.0 *(65)$ & $55.1(49)$ \\
\hline Most religious & $19.1(47)$ & na & $53.1(49)$ & $24.4 *(4 I)$ & $58.9 *(73)$ & $69.1(55)$ \\
\hline
\end{tabular}

$M=$ Males; $F=$ Females; $*=P<0.05$ (chi-square); $n a=$ less than 5 cases in cell and so excluded

Table 3 presents the $X^{2}$ analysis of respondents' age at first sex by religion and religiosity. Although it was only religiosity that was significantly associated with age at first sex and only among females $(P<0.05)$, it is apparent that majority of the respondents got involved in sex between age 12 and 14 years. The proportion was generally higher among females. The association between religiosity and age at first sex was highly significant among females $(P<0.05)$. In all categories of religiosity, majority of female respondents (ranging between $90.1 \%$ and $65.4 \%$ ) had sex within $12-14$ age brackets.

Table 3 Percent of respondents by age at first sex and religion and religiosity, by sex

\begin{tabular}{|c|c|c|c|c|c|c|}
\hline \multirow[t]{2}{*}{ Characteristics } & \multicolumn{2}{|c|}{$\begin{array}{c}\text { Males } \\
\text { Have first sex }\end{array}$} & \multicolumn{4}{|c|}{$\begin{array}{c}\text { Females } \\
\text { Have first sex }\end{array}$} \\
\hline & $12-14$ & $15-19$ & Number & $12-14$ & $15-19$ & Number \\
\hline & $\%$ & $\%$ & & $\%$ & $\%$ & \\
\hline \multicolumn{7}{|l|}{ Religious Affiliation } \\
\hline None/Traditionalist & 85 & 15 & 20 & 90.9 & 9.1 & 11 \\
\hline Islam & 81.9 & 18.1 & 149 & 88.1 & 11.9 & 160 \\
\hline Catholic & 80.9 & 19.1 & $|4|$ & 85.1 & 14.9 & $14 \mid$ \\
\hline Protestants & 86.5 & 13.5 & 185 & 87.3 & 12.7 & 212 \\
\hline \multicolumn{7}{|l|}{ Religiosity } \\
\hline Religious & 81.2 & 18.8 & 32 & $65.4 * *$ & $34.6 * *$ & 26 \\
\hline More Religious & 84.4 & 15.6 & 218 & $85.4 * *$ & $14.6 * *$ & 213 \\
\hline Most Religious & 82.7 & 17.3 & 234 & $90.1 * *$ & 9.9** & 273 \\
\hline
\end{tabular}

** $=P<0.01$ (chi-square)

In Table 4 the results of the logistic regression models are presented. As explained in the section on method, three categorical indicators of risky sexual behaviour (casual sex, more than one sexual partner and did not use condom) were regressed against religious affiliation and religiosity in three logistic models. The objective was to test the hypothesis that religious affiliation and religiosity are likely to significantly influence risky sexual behaviour in the sample. The result indicates that religious affiliation was not significantly related to any of the indicators of risky sexual behaviour in the models. Religiosity was significantly related to having more than one sexual partner among females $(P<0.05)$ within the six months preceding the survey. Females who were more religious were almost 14 times more likely while those who were most religious were over four times more likely to have kept more than one sexual partners than those who were 
just religious (reference category). This finding suggests that middle level religiosity among female adolescents in the sample had more likelihood to engage in multiple sexual partnerships than less religious.

Table 4 Logistic odds ratios on religion, religiosity and three indicators of risky sexual behaviour by sex

\begin{tabular}{|c|c|c|c|c|c|c|}
\hline \multirow[t]{2}{*}{ Characteristics } & \multicolumn{2}{|c|}{ Model I } & \multicolumn{2}{|c|}{ Model 2} & \multicolumn{2}{|c|}{ Model 3} \\
\hline & $M$ & $\mathbf{F}$ & $M$ & $\mathbf{F}$ & $M$ & $\mathbf{F}$ \\
\hline \multicolumn{7}{|c|}{ Religious Affiliation } \\
\hline Islam & 8.077 & na & 9.395 & 0.977 & 0.933 & 1.863 \\
\hline Catholic & 1.836 & 0.842 & 0.981 & 3.347 & 0.739 & 1.1 \\
\hline Protestants & 1.024 & na & 1.764 & 2.165 & $0.76 \mathrm{I}$ & 0.76 \\
\hline \multicolumn{7}{|c|}{ None/Traditionalist (r) } \\
\hline \multicolumn{7}{|l|}{ Religiosity } \\
\hline More religious & 1.039 & na & 0.513 & $13.750 * *$ & 0.356 & 0.333 \\
\hline Most religious & 1.263 & 1.418 & 0.57 & $4.021^{*}$ & 0.455 & 0.569 \\
\hline
\end{tabular}

$M=$ Males; $F=$ Females; model $I=$ Casual sex; mode $2=$ More than one sex partner;

model $3=$ did not use condom; ${ }^{*}=P<0.05$; ${ }^{*}=P<0.01$; na $=$ not included in the model

\section{Discussion}

As mentioned earlier, the study has tested two hypotheses: religious affiliation is likely to significantly influence risky sexual behaviour among adolescents and religiosity is likely to significantly affect risky sexual behaviour among adolescents. In attempt to test these hypotheses, bivariate and multivariate analyses were carried out. The analysis shows that at the bivariate level, out of the four indicators of risky sexual behaviours, religious affiliation was only significantly related to casual sex among males. The relationship paints a picture that is consistent with some aspects of the literature that association with protestant Christian religion is likely to have restraining effect on casual sex among male adolescents (Morhason-Bello et al., 2008; Nishimura et al., 2007; Price \& Granger, 2005). Traditionalist and those who did not belong to any religious groups were more vulnerable to engaging in casual sex. This suggest that young people who do not identify with any of the popular religious groups(Christianity and Islam) were more likely to be exposed to casual sex which has been identified as a behavioural practice that breeds sexual health problems. This observation is critical in view of the fact that a higher proportion of them did not practise condom use. Thus the risk of sexual infections is very high among males that were less religious compared to their more religious counterparts. At this level, it is obvious that religion and religiosity play some significant role in determining the sexual health status of male respondents. On the other hand, just religious affiliation did not play any significant role in female sexual health behaviour. It was religiosity that was significantly related to unprotected sex. In this case, the relationship implies preponderance of unprotected sex among more religious girls. This may not be unconnected with the anti-contraceptive position of some religious leaders. The fact that most of the girls had had sexual intercourse very early (age 12-14 years) indicates a very devastating situation among them with respect to sexual health. Also, although the association was not statistically significant, the percentages indicate that the more religious the girls the more they engaged in unprotected sex which further strengthens the submission that female adolescents are more vulnerable.

At the level of multivariate analysis, the four models indicated that religious affiliation did not have any statistically significant relationship with the four indicators of risky sexual behaviour. In view of the fact that the bivariate association was relatively scanty in terms of the number of the indicators and the gender dimension of it, and the complete disappearance of the relationship at the multivariate level of analysis, it is vivid that the first hypothesis was not valid. This implies that religious affiliation in the context of the study population cannot be considered as a significant predictor of risky sexual behaviour among adolescents in the study population if religiosity is controlled for. Conversely, religiosity was significantly related to having more than one sexual partner among females and unprotected sex among males, and age at first sexual intercourse among females who had sexual initiation at an age above 14 years. At the multivariate level, religiosity was only significantly related to having more than one sexual partner among females. Thus religiosity was only related to one indicator of risky sexual behaviour at both bivariate and multivariate levels of analyses among female adolescents. On the basis of this indicator, the second hypothesis was valid only among female adolescents.

In light of these findings, this study has made some contributions towards resolving the first two of the unresolved differences as highlighted earlier. In the first case, the study found that religious affiliation did not have any significant influence on sexual health behaviour of adolescents in the present context. Analysis of data reveals that majority of the Inkanyiso, Jnl Hum \& Soc Sci 20I I, 3(I) 
adolescents have had the first sexual intercourse at age 14. It is likely that a vast majority of the respondents who had experienced sexual initiation was responsible for the absence of significant relationship between religious affiliation and risky sexual behaviour among them as pointed out in previous studies (Hardy \& Raffaeli, 2003; Rostoky, Regrerus, \& Wright, 2002). In addition, this study supports one aspect of the gender dimension of the unresolved differences which states that the constraining effect of religiosity on adolescents' sexual behaviour was only significant among females (Meier 200I; Rostosky et al., 2004). The fact that the relationship was sustained at bivariate and multivariate levels only among females implies that that religiosity plays a significant role in risky sexual behaviour among females in the context of the study.

\section{Conclusion}

The findings suggest that religious affiliation is not likely to play any significant role in shaping sexual behaviour of young people owing to the fact that it did not manifest any statistically significant relationship with the indicators in the study area. The study indicates that simply identifying with a religion would not be sufficient to influence adolescents towards reducing risky sexual behaviour in the population. However, flowing from the statistically significant relationship between religiosity and having more than one sexual partner among females, religiosity is likely to be a significant channel through which the menace of risky sexual behaviour among female adolescents could be confronted. Therefore, to shape adolescent sexual behaviour, religiosity in terms of regular attendance of religious activities and such like and not just identification with a religious group, should be encouraged among them.

The study suffers some limitations. Firstly, just like any other study on sensitive areas of human life, investigating sexual behaviour among young people is a very difficult task. So, the likelihood of under-reporting or over reporting sexual experiences among males and female respondents respectively, is usually very likely. This problem may have influenced the findings. Secondly, this study adopted a purely cross-sectional design. It is generally agreed that cross-sectional studies are limited in measuring the impact of independent variables on dependent variables. The analysis is also limited because of the use of one item indicator of independent variable. The measurement of religiosity adopted may also have affected the result. Thirdly, generalisation of result about the country is also difficult given that the sample was generated only within one city. However, given that the findings do not deviate significantly from that of previous similar studies, especially in other settings, including those that made use of longitudinal designs, it suggests that the findings provide reliable estimate of current likely influence of religious affiliation and religiosity on the sexual health behaviour of young people in the study setting.

\section{References}

Barnett, R.V., Jackson, T.L., Smith, S., and Gibson, H. 2010. The effects of religiosity and sibling relationship on the timing of sexual debut. Family Science Review, I5, 66-83.

Bankole, A. and Malarcher, S. 2010. Removing barriers to adolescents' Access to contraceptive information and services. Studies in Family Planning, 4I, I I 7-124.

Bongaarts, J., Buethner T., Heilig, G., and Pelletter F. 2008. Has the HIV Epidemic Peaked? Population and Development Review, 34, 199-224.

Doswell, W. M., Konyate, M., and Taylor, J.T. 2003. The role of spirituality in preventing early sexual behaviour. American Journal of Health studies, 18, 195-202.

Durojaiye, C., O. 2009. Knowledge, perception and behaviour of Nigerian youths on HIV/AIDS. Internet Journal of Health, I5288315, 9, http://search.epnet.com. Accessed September, 2010.

Etzkin, R. 2004. How parenting style and religiosity affect the timing of Jewish adolescents' sexual debut. A Master of Science thesis presented to the graduate school of the University of Florida.

Fehring, R.J., German, K., Cheever, K.H., and Philpot, C. 1998. Religiosity and sexual behaviour among older adolescents. An epublication of Marquette University, http://cpublications.marquette.edu/nursing_fac/3/.

Genuis, S.J. 2009. Adolescent sexual behaviour and public health: The religion versus science dichotomy. Acta Paediatrica, A different View Series.

Hardy, S.A. and Raffaelli, M. 2003. Adolescent religiosity and sexuality: an investigation of reciprocal influences. Journal of Adolescence, 26, 731-739.

Jones, R.K., Darroch, J.E., and Singh, S. 2005. Religious differentials in the sexual and reproductive behaviours of young women in the United States. Journal of Adolescent Health, 36, 279-288.

Meier, A.M. 200I. Adolescents' transition to first intercourse, religiosity and attitudes about sex Centre for Demography and Ecology Working Paper No. 200I-02, University of Wisconsin-Madison.

Morhason-Bello, I.O., Oladokun, A., Enakpene, C, A., Fabamiro, A. O., Obisesan, K. A., and Ojengbede , O. A. 2008. Sexual behaviour of in-school adolescents in Ibadan, South-West Nigeria. African Reproductive Health, I2, 89-97.

National Population Commission and ICF Macro. 2009. Nigerian Demographic and Health Survey 2008. Abuja: National Population Commission and ICF Macro.

National Population Commission. 2009. Youth and Adolescent. http://www.population.gov.ng/index.php. Accessed October 2, 2010. 
Nishimura, Y., H., Ono-Kihara, M., Mohith, J.C., Ngmansun, R., Homma, T., DiClemente, R. J., Lang, D. L., and Kihara, M. 2007. Sexual behaviours and their correlates among young people in Mauritius: a cross-sectional study. BMC International Health and Human Rights (electronic version): http://www.biomedcentral.com/l472-698x/7/8.

Odimegwu, C. 2005. Influence of religion on adolescent sexual attitudes and behaviour among Nigerian University students: Affiliation or commitment? African Journal of Reproductive Health, 9, 125- I 40.

Okonofua , F. 2007. New research findings on adolescent reproductive health in Africa. African Journal of Reproductive Health, II, 7-9.

Olurode, L. 2000. Introduction: the role of religion in life. In Olurode, L. (Ed.) Reproductive health within the content of Islam (pp I-I6). Lagos: Islamic Women and Youth Centre.

Price, G. N. and Granger, M. D. 2005. Does religion constrain risky sexual behaviour associated with HIV/AIDS? Mississippi: Mississippi Urban Research Centre.

Rostosky, S. S., Regnerus, M. D., and Wright, M. L.C. 2002. Coital debut: The role of religiosity and sex attitudes in the add health survey. Journal of Sex Research, 40, 358-367.

Rostosky, S.S., Wilcox, B. L., Wright, M. L.C., and Randall, B. A. 2004. The impact of religiosity on adolescent sexual behaviour: A review of the evidence. Journal of Adolescent Research, 19, 677-697.

Santow, G. 2009. Contributions of behavioural change to curbing the spread of HIV. IUSSP Policy and Research Paper number 23. France: IUSSP.

Steinman, K. S. and Zimmerman, M.A. 2004. Religious activity and risky behaviour among African American adolescents: Concurrent and developmental effects. American Journal of Community Psychology, 33, I 5 I- I 6 I

Thornton, A. and Camburn, D. 1989. Religious participation and adolescent sexual behaviour and attitudess. Journal of Marriage and Family, 5 I, 64 I-653. 